\title{
Systemic Approach
}

Dear Reader,

It is not long now until January 2019. That date will mark the introduction of the Stage V emission standard for nonroad mobile machinery in the EU. The most important change compared to the existing Stage IV regulation relates to the particle number (PN) emission limits for diesel engines. Whereas it was previously possible to comply with the emission limits without a particulate filter, many experts believe that the use of a diesel particulate filter will become absolutely essential from 2019 onwards. What is good for people's health presents a difficult challenge for the developers of powertrains, as they need to integrate an additional component into the already limited space in the engine compartment - not to mention an increase in the price of the machinery, which they will have to justify to the buyers.

Sooner or later, there will also be a legal limit for the $\mathrm{CO}_{2}$ emissions of mobile machinery. The industry has long since recognised its responsibility in this respect and is carrying out research into finding solutions, or is even already producing hybrid powertrains which also contribute to improvements in fuel consumption and $\mathrm{CO}_{2}$ emissions.

However, only few countries can afford such low-emission machines, and most nations permit the use of machinery with much higher emission levels. For that reason, politicians should pursue a systemic approach - as the industry is already doing in the development of its machines - and focus not only on diesel engine manufacturers, but also on fuel producers. Modern machines are still being powered by fossil fuels. And yet, synthetic fuels would offer considerable benefits. But even in the foreseeable future, these will not be available at affordable prices. The oil-processing industry must therefore also be made to play its part, for example by being required to sell an increasing proportion of synthetic fuels in relation to fossil fuels. That would be a systemic approach towards reducing global emissions. And as a result, it would not only be new Stage $V$ engines that help to protect the environment, but also older vehicles.

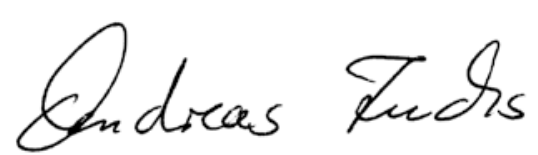

Andreas Fuchs

Chief Correspondent

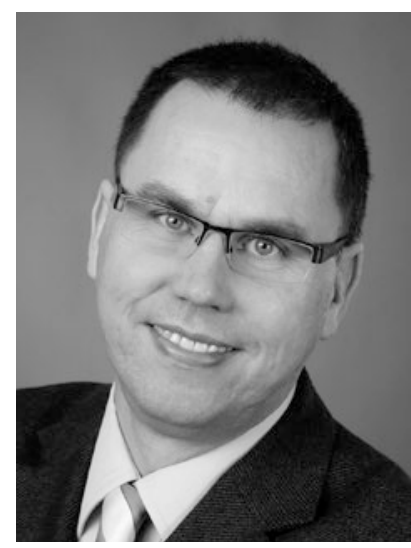

